\title{
Metformin overdose, but not lactic acidosis per se, inhibits oxygen consumption in pigs
}

Alessandro Protti ${ }^{1 *}$, Francesco Fortunato ${ }^{2}$, Massimo Monti ${ }^{1}$, Sarah Vecchio ${ }^{3}$, Stefano Gatti ${ }^{4}$, Giacomo P Comi $^{2}$, Rachele De Giuseppe ${ }^{5}$ and Luciano Gattinoni ${ }^{1}$

\begin{abstract}
Introduction: Hepatic mitochondrial dysfunction may play a critical role in the pathogenesis of metformin-induced lactic acidosis. However, patients with severe metformin intoxication may have a 30 to $60 \%$ decrease in their global oxygen consumption, as for generalized inhibition of mitochondrial respiration. We developed a pig model of severe metformin intoxication to validate this clinical finding and assess mitochondrial function in liver and other tissues.

Methods: Twenty healthy pigs were sedated and mechanically ventilated. Ten were infused with a large dose of metformin ( 4 to $8 \mathrm{~g}$ ) and five were not (sham controls). Five others were infused with lactic acid to clarify whether lactic acidosis per se diminishes global oxygen use. Arterial pH, lactatemia, global oxygen consumption $\left(\mathrm{VO}_{2}\right)$ (metabolic module) and delivery $\left(\mathrm{DO}_{2}\right)$ (cardiac output by thermodilution) were monitored for nine hours. Oxygen extraction was computed as $\mathrm{VO}_{2} / \mathrm{DO}_{2}$. Activities of the main components of the mitochondrial respiratory chain (complex I, II and III, and IV) were measured with spectrophotometry (and expressed relative to citrate synthase activity) in heart, kidney, liver, skeletal muscle and platelets taken at the end of the study.
\end{abstract}

Results: Pigs infused with metformin ( $6 \pm 2 \mathrm{~g}$; final serum drug level $77 \pm 45 \mathrm{mg} / \mathrm{L}$ ) progressively developed lactic acidosis (final arterial pH $6.93 \pm 0.24$ and lactate $18 \pm 7 \mathrm{mmol} / \mathrm{L}, P<0.001$ for both). Their $\mathrm{VO}_{2}$ declined over time (from $115 \pm 34$ to $71 \pm 30 \mathrm{ml} / \mathrm{min}, P<0.001$ ) despite grossly preserved $\mathrm{DO}_{2}$ (from $269 \pm 68$ to $239 \pm 51 \mathrm{ml} / \mathrm{min}, P$ $=0.58)$. Oxygen extraction accordingly fell from $43 \pm 10$ to $30 \pm 10 \%(P=0.008)$. None of these changes occurred in either sham controls or pigs infused with lactic acid (final arterial pH $6.86 \pm 0.16$ and lactate $22 \pm 3 \mathrm{mmol} / \mathrm{L}$ ). Metformin intoxication was associated with inhibition of complex I in the liver $(P<0.001)$, heart $(P<0.001)$, kidney $(P=0.003)$, skeletal muscle $(P=0.012)$ and platelets $(P=0.053)$. The activity of complex $I I$ and III diminished in the liver $(P<0.001)$, heart $(P<0.001)$ and kidney $(P<0.005)$ while that of complex IV declined in the heart $(P<0.001)$.

Conclusions: Metformin intoxication induces lactic acidosis, inhibits global oxygen consumption and causes mitochondrial dysfunction in liver and other tissues. Lactic acidosis per se does not decrease whole-body respiration.

\section{Introduction}

Metformin is the drug of choice for adults with type 2 diabetes [1]. It is a safe drug [2] although lactic acidosis rarely develops as a side effect [3-5]. In most of the cases, drug use is only coincidental and lactic acidosis is due to concomitant hypoxia, tissue hypoperfusion or

\footnotetext{
* Correspondence: alessandro.protti@policlinico.mi.it

'Dipartimento di Anestesia, Rianimazione (Intensiva e Sub-Intensiva) e Terapia del Dolore, Fondazione IRCCS Ca' Granda - Ospedale Maggiore Policlinico, Università degli Studi di Milano, Via Francesco Sforza 35, Milano 20122, Italy

Full list of author information is available at the end of the article
}

liver failure (metformin-associated lactic acidosis) [6]. Less frequently, no other major risk factor can be identified and drug accumulation, prompted by renal failure for instance, is the most probable cause of the syndrome (metformin-induced lactic acidosis) [7].

The pathogenesis of metformin-induced lactic acidosis remains unclear. Some authors even question whether metformin per se can cause lactic acidosis [8]. Some others mainly attribute it to changes in liver lactate metabolism [9]. Metformin readily accumulates in hepatocytes, that express the organic cation transporter 1 [10], and inhibits their mitochondrial respiration in a
C Biomed Central 
dose-dependent manner [11-13]. As a possible result, liver lactate output increases [11-13] and uptake decreases (along with gluconeogenesis) [12,14]. However, critically ill metformin-intoxicated patients may have a 30 to $60 \%$ decrease in their global oxygen extraction and consumption [7], as for generalized (and not solely hepatic) mitochondrial dysfunction. Lactate overproduction from tissues other than the liver may then occur [15].

The aim of the present study was to clarify whether metformin intoxication inhibits whole-body respiration and alters mitochondrial function in the liver and other tissues.

\section{Materials and methods}

The study complied with international recommendations [16] and was approved by the Italian Ministry of Health (protocol number 212).

\section{Surgical preparation}

Twenty healthy pigs $(22 \pm 2 \mathrm{~kg})$ were sedated with tiletamine/zolazepam ( $5 \mathrm{mg} / \mathrm{kg}$ intramuscular (IM)) and medetomidine hydrochloride $(0.025 \mathrm{mg} / \mathrm{kg} \mathrm{IM})$ and infused with ceftriaxone (1 $\mathrm{g}$ intravenous (IV)), propofol (50 mg IV) and tramadol (50 mg IV). Tracheotomy and cystostomy were performed and carotid artery, internal jugular vein and pulmonary artery were cannulated. Thereafter, mechanical ventilation (oxygen inspiratory fraction of 0.5 ) and infusion of propofol (80 to $100 \mathrm{mg} /$ hour), medetomidine $(50 \mu \mathrm{g} / \mathrm{hour}$ ), pancuronium bromide ( 8 to $10 \mathrm{mg} /$ hour) and saline (50 ml/hour) were kept constant until end of the experiment.

\section{Study design}

After six hours of stabilization and baseline recordings (time 0 ), ten pigs were infused with 4 to $8 \mathrm{~g}$ of metformin hydrochloride (Sigma-Aldrich; St. Louis, MO, USA) (1.6 g in $20 \mathrm{ml}$ of saline per hour, over 2.5 to 5 hours) and five were not (sham controls). Five other pigs were continuously infused with lactic acid (30\% in water) (Sigma-Aldrich) to clarify whether lactic acidosis (that always developed in animals treated with metformin) directly inhibits global oxygen consumption. Lactic acid infusion was hourly adjusted to mimic the rise in lactatemia observed in metformin-intoxicated pigs.

Data collection always lasted nine hours (animals were then sacrificed). Arterial and mixed venous blood gases, lactatemia and glycaemia were measured every hour. Oxygen delivery $\left(\mathrm{DO}_{2}\right)$ was calculated as: $13.6 * \mathrm{CO}^{*} \mathrm{Hb}^{*} \mathrm{SaO}_{2}$, where $\mathrm{CO}, \mathrm{Hb}$ and $\mathrm{SaO}_{2}$ are cardiac output (thermodilution), arterial haemoglobin concentration and oxygen saturation. Oxygen consumption $\left(\mathrm{VO}_{2}\right)$ was measured with a COVX metabolic module (GE Healthcare; Madison, WI, USA) and extraction computed as $\mathrm{VO}_{2} / \mathrm{DO}_{2}$. Water balance was calculated as the difference between overall saline input and urinary output. In pigs infused with metformin, final (time nine) serum drug concentration was measured with high performance liquid chromatography.

Hypotension (mean arterial pressure $<60 \mathrm{mmHg}$ ) was always treated with additional saline and norepinephrine, hypoglycaemia $(<60 \mathrm{mg} / \mathrm{dl})$ with glucose and hypothermia (body core temperature $<37^{\circ} \mathrm{C}$ ) with active warming.

Further investigations were only performed in pigs infused with metformin and sham controls.

\section{Mitochondrial function tests}

Before sacrifice, ethylenediaminetetraacetic acid-anticoagulated blood was collected and sedimented for $45 \mathrm{~min}$ utes at $4^{\circ} \mathrm{C}$. The top three-quarters of platelet-rich plasma were washed with distilled water, centrifuged at $5000 \mathrm{~g}$ for 10 minutes (14500 g from the second cycle on) and washed with phosphate-buffered saline until a clear platelet pellet could be stored at $-80^{\circ} \mathrm{C}$ (two to three cycles were usually required). After sacrifice $(\mathrm{KCl} 40 \mathrm{mEq}$ IV), samples of heart, liver, kidney and skeletal muscle were immediately stored in liquid nitrogen.

At the time of analysis, platelet pellet was diluted in buffer $(300$ to $400 \mu \mathrm{l})(\mathrm{KCl} 120 \mathrm{mM}$, ethyl piperazine ethane sulfonic acid $20 \mathrm{mM}, \mathrm{MgCl}_{2} 5 \mathrm{mM}$ and ethylene glycol tetraacetic acid $1 \mathrm{mM} ; \mathrm{pH} 7.2$ ), sonicated (two cycles at $60 \mathrm{~W}$ for 10 seconds) and then centrifuged (750 g for 10 minutes) while kept at $4^{\circ} \mathrm{C}$. Tissue fragments were diluted (1:10) in the same buffer, homogenized (three cycles at $350 \mathrm{~g}$ for one minute) and centrifuged as above. We measured the activity of respiratory chain nicotinamide adenine dinucleotide-ubiquinone 1 reductase (complex I), succinate-cytochrome c reductase (complex II + III) and cytochrome c oxidase (complex IV) on supernatants, using spectrophotometry (at $30^{\circ} \mathrm{C}$ ). Results are expressed relative to citrate synthase activity, a marker of mitochondrial content [17]. Proteins were measured with Lowry's method.

\section{Lactate-to-pyruvate ratio}

At the end of the study, blood was withdrawn from six intoxicated and five control animals into heparinized tubes and immediately centrifuged (2500 g for 10 minutes). Plasma was then stored at $-80^{\circ} \mathrm{C}$. Lactate and pyruvate levels were measured on perchloric acid-deproteinezed plasma using high-performance liquid chromatography. Final lactate-to-pyruvate ratios were calculated.

\section{Oxidative stress}

Final serum reactive oxygen species and total antioxidant capacity were measured with d-ROMs and Oxy-adsorbent tests (Diacron International; Grosseto, Italy) [18]. These assays are based on spectrophotometric quantification of a 
color compound that forms in response to oxidation. The d-ROMs test evaluates the concentration of reactive oxygen metabolites, namely hydroperoxides. Results are expressed in arbitrary units, called U Carr (one U Carr corresponds to $0.08 \mathrm{mg} / \mathrm{dl}$ of hydrogen peroxide). The Oxy-adsorbent test measures the overall capacity of a biological sample to absorb exogenous hypochlorous acid $(\mathrm{HClO})$. Results are expressed as the maximum concentration of hypochlorous acid that can be absorbed by the sample.

\section{Statistical analysis}

Data are reported as mean and standard deviation (SD). Based on distribution (Shapiro-Wilk test), we used Student's $t$ or Wilcoxon rank sum tests to compare two groups. Interactions between groups and time were tested with two-way repeated measures analysis of variance. Non-normally distributed data were firstly transformed in ranks [19]. Unless otherwise stated, $P$ values reported in brackets refer to analysis of these interactions. Post hoc comparisons were performed with Holm-Sidak method. Correlations were tested with linear regression analysis $\left(R^{2}\right)$. A $P$ value $<0.05$ was considered statistically significant (SigmaPlot version 11.0, Jandel Scientific Software; San Jose, CA, USA).

\section{Results}

All animals survived until end of the study. In sham controls, none of the variables of interest changed over time (Figure 1, Additional file 1). Conversely, pigs infused with metformin ( $6 \pm 2 \mathrm{~g}$; final serum drug concentration $77 \pm$ 45 (range 3 to 146) $\mathrm{mg} / \mathrm{L}$ ) had, on average, severe lactic acidosis (final arterial pH $6.93 \pm 0.24$ (range 6.80 to 7.57 ); lactate $18 \pm 7$ (range 1 to 24$) \mathrm{mmol} / \mathrm{L}$ ) (Figure 1). Arterial $\mathrm{pH}$ decreased and lactatemia increased proportionally to final serum metformin level $\left(\mathrm{R}^{2} 0.54, P=0.015\right.$ and $\mathrm{R}^{2}$ $0.40, P=0.049$, respectively). Hypoglycaemia usually developed $(P=0.002)$ : more glucose was infused, on average, in intoxicated than in control animals $(15 \pm 7$ vs. $3 \pm$ $5 \mathrm{ml} /$ hour of a $33 \%$ solution; $P=0.003$ ).

Metformin intoxication progressively inhibited global oxygen extraction $(P=0.008)$ and consumption $(P<$ 0.001 ) and increased mixed venous oxygen saturation (from $65 \pm 6$ up to $78 \pm 7 \%, P<0.001$ ), despite no change in oxygen delivery $(P=0.58)$ (Figure 1$)$. The overall rise in blood lactate levels was proportional to the decrease in global oxygen use $\left(\mathrm{R}^{2} 0.70, P=0.002\right)$. Body temperature fell from $38.0 \pm 2.0$ to $36.6 \pm 1.2^{\circ} \mathrm{C}(P<0.001)$.

Hemodynamic changes are shown in Additional file 1. Pigs infused with metformin became hypotensive $(P<$ 0.001 ) and therefore received much more fluids (final water balance $1172 \pm 834$ vs. $-139 \pm 242 \mathrm{ml}, P=0.011)$ and norepinephrine $(<0.001)$ than controls. Cardiac output (not measured in one case) never significantly changed $(P=1.0)$.

Infusion of lactic acid decreased arterial $\mathrm{pH}$ (down to $6.86 \pm 0.16$ ) and increased lactatemia (up to $22 \pm$ $3 \mathrm{mmol} / \mathrm{L}$ ) just as metformin did. Nonetheless, global oxygen use and extraction augmented $(P<0.001$ for both), mixed venous oxygen saturation diminished (from $65 \pm 11$ down to $39 \pm 14 \%, P<0.001)$ and delivery slightly, spontaneously, increased $(P=0.017)$ (Figure 2$)$. Hemodynamic changes are reported in Additional file 2.

\section{Mitochondrial function tests}

Relative to sham controls, respiratory chain enzymes were variably inhibited in pigs infused with metformin (Figure 3). Complex I activity was lower in liver $(P<$ $0.001)$, heart $(P<0.001)$, kidney $(P=0.003)$, skeletal muscle $(P=0.012)$ and platelets $(P=0.053)$. The activity of complex II and III was inhibited in liver $(P<0.001)$, heart $(P<0.001)$ and kidney $(P<0.005)$ while that of complex IV was low in heart $(P<0.001)$. Citrate synthase activity slightly increased in kidney $(P=0.003)$ and liver $(P=0.066)$.

\section{Lactate-to-pyruvate ratio}

Intoxicated pigs had final plasma pyruvate levels slightly higher (197 \pm 52 vs. $121 \pm 23 \mu \mathrm{mol} / \mathrm{L}, P=0.08)$ and lactate-to-pyruvate ratios largely higher $(122 \pm 32$ vs. $10 \pm 2$, $P<0.001)$ than controls.

\section{Oxidative stress}

Final serum reactive oxygen species $(590 \pm 153$ vs. $628 \pm$ 85 U Carr, $P=0.632)$ and total antioxidant capacity (227 \pm 64 vs. $218 \pm 33 \mu \mathrm{mol} \mathrm{HClO} / \mathrm{ml}, P=0.767$ ) did not differ between intoxicated and control animals.

\section{Discussion}

This work demonstrates that metformin intoxication: 1) causes lactic acidosis; 2) inhibits oxygen consumption (while lactic acidosis per se does not) and 3) impairs mitochondrial function in liver and other tissues.

Lactic acidosis is commonly due to cellular hypoxia [20]. Whenever oxygen delivery diminishes relative to demand, extraction increases to maintain a normal aerobic (mitochondrial) energy production. When this compensatory mechanism is exhausted, anaerobic (extramitochondrial) glycolysis accelerates, lactate production increases [21] and acidosis develops. Lactate released from skeletal muscle into systemic circulation to be taken up as an energy substrate by distal organs may further increase blood lactate levels [22].

Lactic acidosis can also occur independently from cellular hypoxia [23,24], as in these experiments. In fact, following metformin infusion in healthy pigs, oxygen 


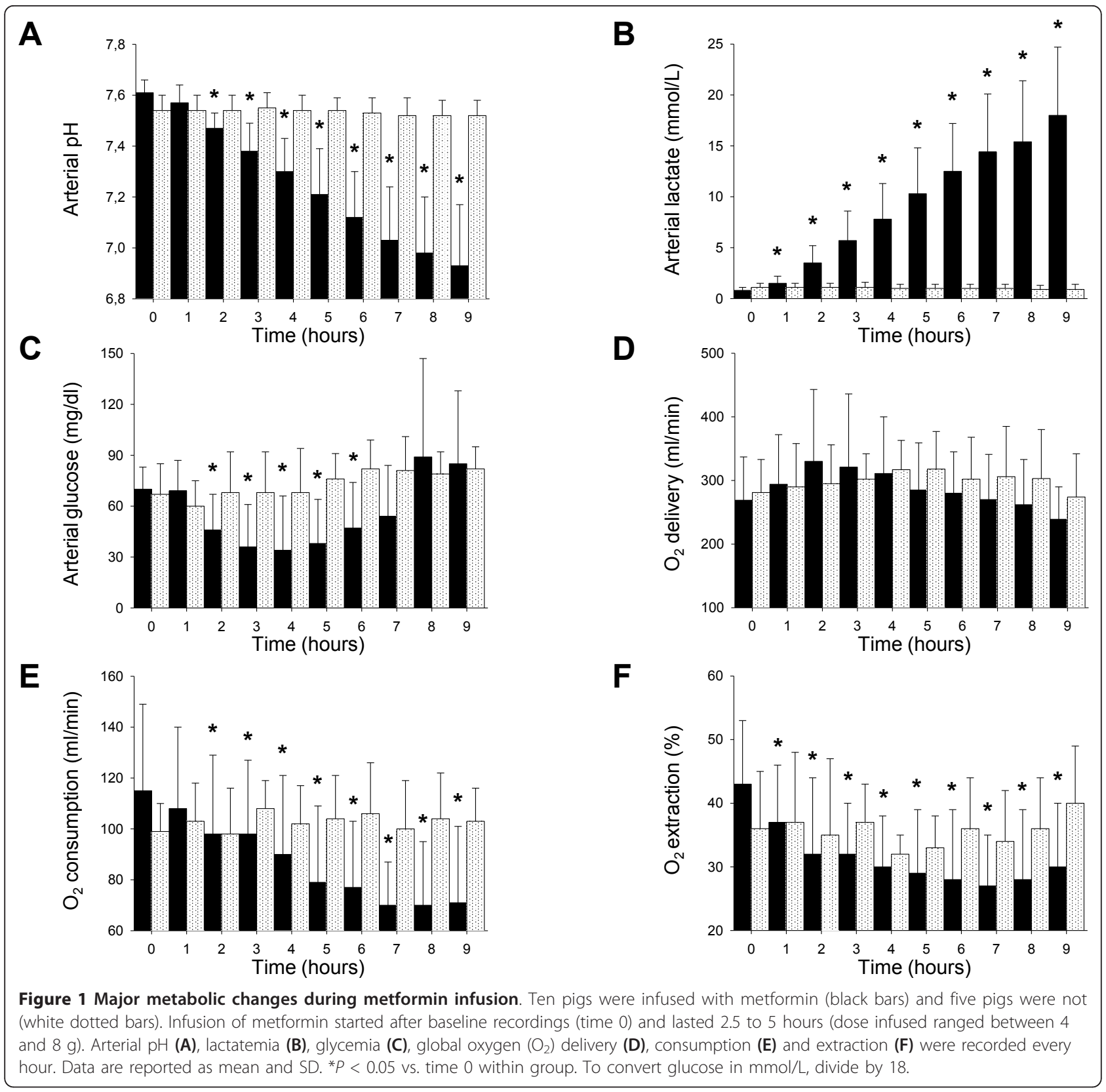

use declined and lactic acidosis arose only because oxygen extraction, but not delivery, diminished. Accordingly, mixed venous oxygen saturation increased, suggesting that delivery even exceeded demand. The decline in body temperature further indicates hypometabolism. These data confirm our previous clinical findings: patients with lactic acidosis due to metformin accumulation have abnormally low oxygen extraction and consumption, high venous oxygen tension and are usually hypothermic [7]. Severe metformin intoxication therefore resembles cyanide poisoning [25], when cells become unable to use otherwise available oxygen and energy production largely depends on glycolysis. The fact that oxygen consumption never diminished in animals infused with lactic acid (and no metformin) demonstrates that lactic acidosis per se cannot explain our present findings.

Serum metformin levels in intoxicated pigs $(77 \pm 45$ $\mathrm{mg} / \mathrm{L}$ ) were similar to those we have previously recorded in humans $(61 \pm 25 \mathrm{mg} / \mathrm{L}$; therapeutic level is $<4 \mathrm{mg} / \mathrm{L})$ [7]. Severity of intoxication in pigs correlated with that of lactic acidosis. One single animal had a normal final serum drug concentration (possibly due to efficient drug urinary excretion) with only mild and transient 


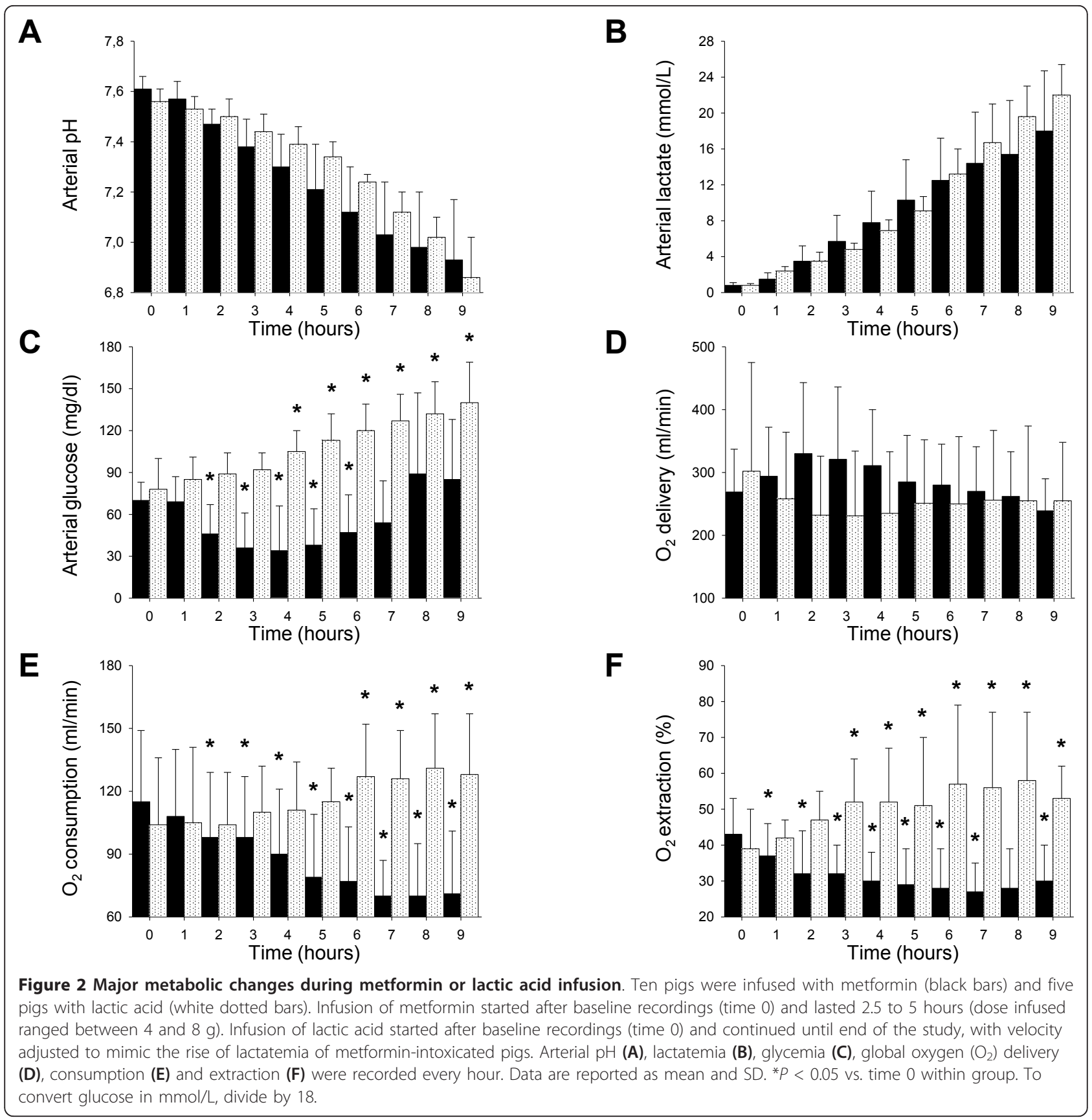

metabolic alterations. All other pigs had clearly toxic serum drug levels with overt and persistent lactic acidosis.

Metformin variably accumulates in virtually every tissue [26]. In vitro, it dose-dependently inhibits mitochondrial function even in cells other than hepatocytes [27-32]. We have now shown that, in vivo and at toxic dose, it causes mitochondrial dysfunction not just in liver but also in heart, kidney, skeletal muscle and platelets (with differences in severity possibly explained by uneven drug distribution). Lower global oxygen use may thus reflect a generalized inhibition of mitochondrial respiration, which may lead to hepatic and extra-hepatic lactate overproduction. The large increase in blood lactate-to-pyruvate ratios may consistently signal accelerated glycolysis and lactate generation in face of diminished mitochondrial energy production [33].

Previous reports have shown that chronic therapeutic levels of metformin can stimulate mitochondrial biogenesis [34], the process by which cells form new mitochondria. Increased citrate synthase activity in kidney and liver is consistent with this finding. But still, in our present 

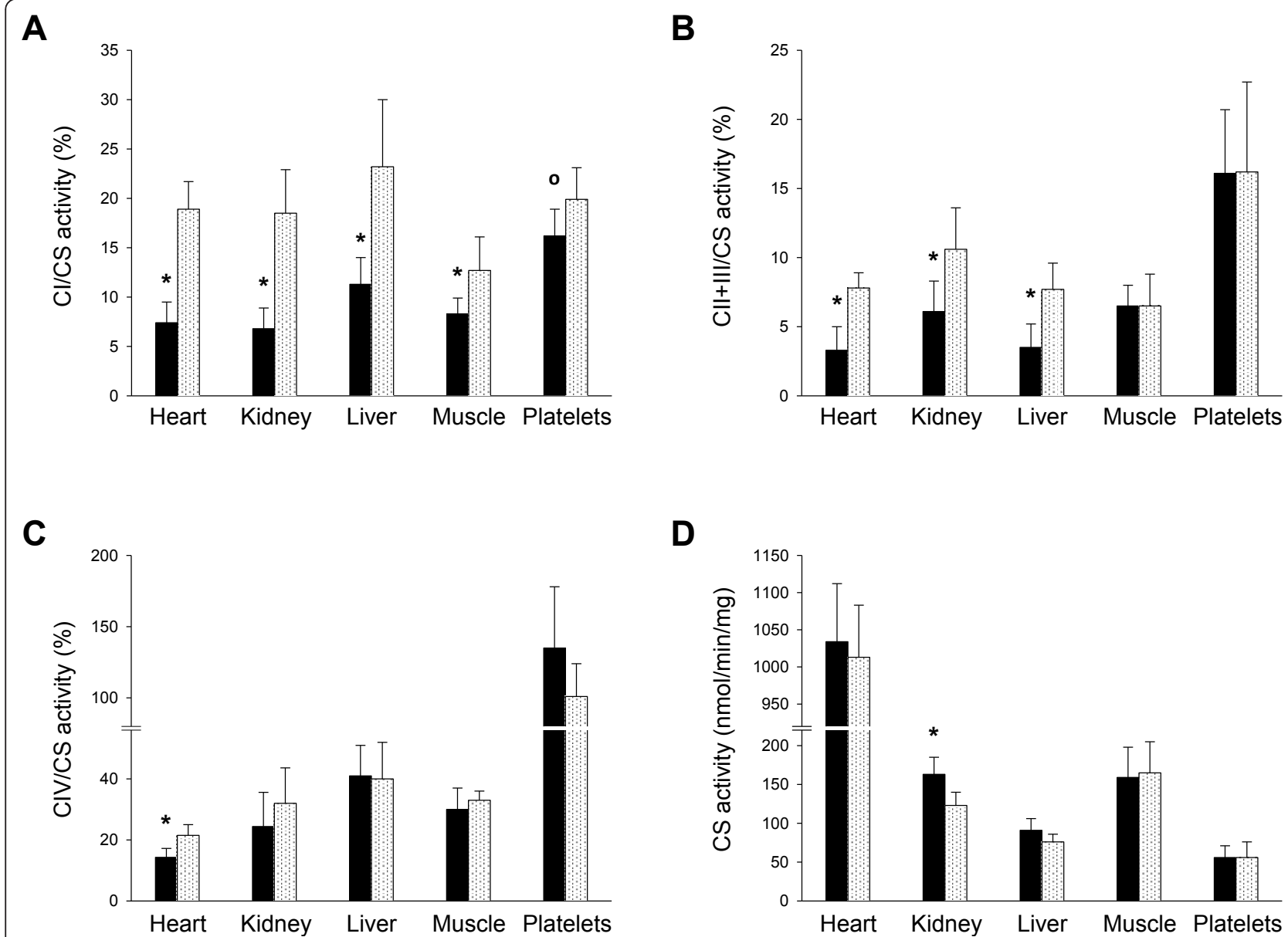

Figure 3 Mitochondrial changes following metformin intoxication. Ten pigs were infused with metformin (black bars) and five pigs were not (white dotted bars). Activities of complex I (CI) (A), complex II and III (CII+III) (B) complex IV (CIV) (C) and citrate synthase (CS) (D) were measured at the end of study in heart, kidney, liver, skeletal muscle and platelets. Data are reported as mean and SD. ${ }^{\circ} P=0.05$ vs. saline. ${ }^{*} P<$ 0.05 vs. saline. Platelet mitochondrial function was only measured in seven of the intoxicated pigs.

model of acute intoxication, mitochondrial function was mainly, largely, depressed. Other molecules variably modulate mitochondrial metabolism depending on dose and time of administration. For instance, low levels of nitric oxide chronically stimulate mitochondrial biogenesis [35] whereas toxic levels acutely inhibit respiratory chain enzymes [36].

How metformin affects mitochondrial function remains controversial $[11,12]$ and our study did not specifically address this issue. It may increase the formation of reactive oxygen species [37] that may ultimately disrupt mitochondrial integrity [38]. However, we could not demonstrate any clear change in serum markers of oxidative stress following metformin intoxication. Mitochondrial dysfunction in platelets, that are anucleated cells, suggests that de novo, nuclear-encoded, messengers may not be required.

Some of the limitations of this study deserve a comment. First, we used healthy pigs whereas patients with accidental metformin intoxication typically suffer from diabetes, renal failure and other comorbidities. Doing so, we aimed at investigating the pure effect of drug accumulation on global oxygen use and metabolism. Second, pigs infused with metformin also received much more fluids and norepinephrine (to treat hypovolemia and systemic vasodilatation) and glucose (to correct hypoglycaemia) than controls. None of these other factors, however, can explain our present findings. In fact, respiratory chain enzymes activities were expressed relative to citrate synthase activity, to correct for any difference in mitochondrial density (possibly due to edema, for instance). Norepinephrine increases oxygen consumption in vivo [39] and does not grossly alter porcine hepatic and skeletal muscle mitochondrial respiration in vitro $[40,41]$. Although (intracellular) hypoglycaemia can diminish oxygen consumption, it can hardly explain lactate overproduction, since lactate is generated from glucose. Notably, changes in oxygen consumption and blood lactate levels 
persisted even when hypoglycaemia was reversed. Third, cellular respiration and lactate generation were not directly measured.

\section{Conclusions}

The development of lactic acidosis during metformin intoxication is associated with diminished global oxygen consumption and clear evidence of mitochondrial dysfunction in liver and other tissues. Lactic acidosis per se does not inhibit whole-body respiration.

\section{Key messages}

- Severe metformin intoxication largely decreases global oxygen consumption and impairs mitochondrial function in heart, kidney, liver, skeletal muscle and platelets of otherwise healthy pigs.

- Lactic acidosis per se does not decrease wholebody respiration.

- Diffuse inhibition of cellular respiration and secondary lactate overproduction may contribute to the development of metformin-induced lactic acidosis.

\section{Additional material}

Additional file 1: Hemodynamic changes during metformin infusion Ten pigs were infused with metformin and five others were not. Changes in heart rate, mean arterial pressure, cardiac output, diuresis, saline and norepinephrine infusion are reported.

Additional file 2: Hemodynamic changes during metformin or lactic acid infusion. Ten pigs were infused with metformin and five others with lactic acid. Changes in heart rate, mean arterial pressure, cardiac output, diuresis, saline and norepinephrine infusion are reported.

\section{Abbreviations}

$\mathrm{CO}$ : cardiac output; $\mathrm{DO}_{2}$ : global oxygen delivery; $\mathrm{Hb}$ : haemoglobin; $\mathrm{HClO}$ : hypochlorous acid; IM: intramuscular; IV: intravenous; $\mathrm{O}_{2}$ : oxygen; $\mathrm{SaO}_{2}$ : arterial oxygen saturation; SD: standard deviation; $\mathrm{VO}_{2}$ : global oxygen consumption.

\section{Acknowledgements}

We are grateful to Fabio Ambrosetti (Università degli Studi di Milano, Milan, Italy) for valuable technical support and Prof. Enzo Nisoli (Università degli Studi di Milano, Milan, Italy) for insightful comments and suggestions on review of the manuscript.

Preliminary results have been presented in abstract form at the $23^{\text {rd }} \mathrm{ESICM}$ Annual Meeting (Spain, 2010).

\section{Author details}

'Dipartimento di Anestesia, Rianimazione (Intensiva e Sub-Intensiva) e Terapia del Dolore, Fondazione IRCCS Ca' Granda - Ospedale Maggiore Policlinico, Università degli Studi di Milano, Via Francesco Sforza 35, Milano 20122, Italy. ${ }^{2}$ Centro Dino Ferrari - Dipartimento di Scienze Neurologiche, Fondazione IRCCS Ca' Granda - Ospedale Maggiore Policlinico, Università degli Studi di Milano, Via Francesco Sforza 35, Milano 20122, Italy. ${ }^{3}$ Centro Nazionale di Informazione Tossicologica - Centro Antiveleni, Fondazione IRCCS Salvatore Maugeri, Via Salvatore Maugeri 10, Pavia 27100, Italy. ${ }^{4}$ Centro di Ricerche Chirurgiche Precliniche, Fondazione IRCCS Ca' Granda - Ospedale Maggiore Policlinico, Università degli Studi di Milano, Via Francesco Sforza 35, Milano 20122, Italy. ${ }^{5}$ Fondazione Fratelli Confalonieri, Dipartimento di Scienze Mediche, Università degli Studi di Milano, Fondazione IRCCS Ca'
Granda - Ospedale Maggiore Policlinico, Via Francesco Sforza 35, Milano 20122, Italy.

\section{Authors' contributions}

AP conceived the study, ran the experiments, performed the analysis and wrote the manuscript. FF measured mitochondrial enzyme activities and participated in data analysis. MM ran the experiments. SV participated in data analysis and helped to draft the manuscript. SG participated in the study design and ran the experiments. GPC participated in the study design and analysis. RDG measured markers of oxidative stress. LG participated in the study design and helped to draft the manuscript. All authors read and approved the final version of the manuscript.

\section{Competing interests}

The authors declare that they have no competing interests.

Received: 6 February 2012 Revised: 19 April 2012

Accepted: 8 May 2012 Published: 8 May 2012

\section{References}

1. Nathan DM, Buse JB, Davidson MB, Ferrannini E, Holman RR, Sherwin R, Zinman B, American Diabetes Association, European Association for the Study of Diabetes: Medical management of hyperglycaemia in type 2 diabetes: a consensus algorithm for the initiation and adjustment of therapy: a consensus statement of the American Diabetes Association and the European Association for the Study of Diabetes. Diabetologia 2009, 52:17-30.

2. Salpeter SR, Greyber E, Pasternak GA, Salpeter EE: Risk of fatal and nonfatal lactic acidosis with metformin use in type 2 diabetes mellitus. Cochrane Database Syst Rev 2010, 4:CD002967.

3. Peters N, Jay N, Barraud D, Cravoisy A, Nace L, Bollaert PE, Gibot S: Metformin-associated lactic acidosis in an intensive care unit. Crit Care 2008, 12:R149.

4. Seidowsky A, Nseir S, Houdret N, Fourrier F: Metformin-associated lactic acidosis: a prognostic and therapeutic study. Crit Care Med 2009, 37:2191-2196.

5. Friesecke $S$, Abel $P$, Roser M, Felix SB, Runge S: Outcome of severe lactic acidosis associated with metformin accumulation. Crit Care 2010, 14:R226.

6. Lalau JD, Race JM: Lactic acidosis in metformin therapy: searching for a link with metformin in reports of 'metformin-associated lactic acidosis'. Diabetes Obes Metab 2001, 3:195-201.

7. Protti A, Russo R, Tagliabue P, Vecchio S, Singer M, Rudiger A, Foti G, Rossi A, Mistraletti G, Gattinoni L: Oxygen consumption is depressed in patients with lactic acidosis due to biguanide intoxication. Crit Care 2010, 14:R22.

8. Stacpoole PW: Metformin and lactic acidosis: guilt by association? Diabetes Care 1998, 21:1587-1588.

9. Wang DS, Kusuhara H, Kato $Y$, Jonker JW, Schinkel AH, Sugiyama Y: Involvement of organic cation transporter 1 in the lactic acidosis caused by metformin. Mol Pharmacol 2003, 63:844-848.

10. Wang DS, Kusuhara $H$, Kato $Y$, Jonker JW, Schinkel AH, Sugiyama $Y$ : Involvement of organic cation transporter 1 in hepatic and intestinal distribution of metformin. J Pharmacol Exp Ther 2002, 302:510-515.

11. El-Mir MY, Nogueira V, Fontaine $E$, Avéret $N$, Rigoulet $M$, Leverve $X$ : Dimethylbiguanide inhibits cell respiration via an indirect effect targeted on the respiratory chain complex I. J Biol Chem 2000, 275:223-228.

12. Owen MR, Doran E, Halestrap AP: Evidence that metformin exerts its antidiabetic effects through inhibition of complex 1 of the mitochondrial respiratory chain. Biochem J 2000, 348:607-614.

13. Dykens JA, Jamieson J, Marroquin L, Nadanaciva S, Billis PA, Will Y: Biguanide-induced mitochondrial dysfunction yields increased lactate production and cytotoxicity of aerobically-poised HepG2 cells and human hepatocytes in vitro. Toxicol Appl Pharmacol 2008, 233:203-210.

14. Radziuk J, Zhang Z, Wiernsperger N, Pye S: Effects of metformin on lactate uptake and gluconeogenesis in the perfused rat liver. Diabetes 1997 , 46:1406-1413.

15. Bailey $\mathrm{CJ}$, Wilcock C, Scarpello JH: Metformin and the intestine. Diabetologia 2008, 51:1552-1553.

16. Institute of Laboratory Animal Resources, Commission on Life Sciences, National Research Council: Guide for the care and use of laboratory animals Washington; 1996. 
17. Ragan Cl, Wilson MT, Darley-Usmar VM, Lowe PN: Subfractionation of mitochondria and isolation of the proteins of oxidative phosphorylation. In Mitochondria: a practical approach. Edited by: Darley-Usmar VM Rickwood D, Wilson MT. Oxford: IRL Press; 1987:79-112.

18. Campise M, Bamonti F, Novembrino C, Ippolito S, Tarantino A, Cornelli U, Lonati S, Cesana BM, Ponticelli C: Oxidative stress in kidney transplant patients. Transplantation 2003, 76:1474-8.

19. Conover WJ, Iman RL: Rank transformations as a bridge between parametric and non-parametric statistics. American Statistician 1981, 35:124-129.

20. Cohen PJ: The metabolic function of oxygen and biochemical lesions of hypoxia. Anesthesiology 1972, 37:148-177.

21. Ronco JJ, Fenwick JC, Tweeddale MG, Wiggs BR, Phang PT, Cooper DJ, Cunningham KF, Russell JA, Walley KR: Identification of the critical oxygen delivery for anaerobic metabolism in critically ill septic and non septic humans. JAMA 1993, 270:1724-1730.

22. Brooks GA: Cell-cell and intracellular lactate shuttles. J Physio/ 2009, 587:5591-5600.

23. James JH, Luchette FA, McCarter FD, Fischer JE: Lactate is an unreliable indicator of tissue hypoxia in injury or sepsis. Lancet 1999, 354:505-508.

24. Levy B, Gibot S, Franck P, Cravoisy A, Bollaert PE: Relation between muscle $\mathrm{Na}^{+} \mathrm{K}^{+}$ATPase activity and raised lactate concentrations in septic shock: a prospective study. Lancet 2005, 365:871-875.

25. Peddy SB, Rigby MR, Shaffner DH: Acute cyanide poisoning. Pediatr Crit Care Med 2006, 7:79-82.

26. Wilcock C, Bailey CJ: Accumulation of metformin by tissues of the normal and diabetic mouse. Xenobiotica 1994, 24:49-57.

27. Brunmair B, Staniek K, Gras F, Scharf N, Althaym A, Clara R, Roden M, Gnaiger E, Nohl H, Waldhäusl W, Fürnsinn C: Thiazolidinediones, like metformin, inhibit respiratory complex I: a common mechanism contributing to their antidiabetic actions? Diabetes 2004, 53:1052-1059.

28. El-Mir MY, Detaille D, R-Villanueva G, Delgado-Esteban M, Guigas B, Attia S, Fontaine $E$, Almeida A, Leverve $X$ : Neuroprotective role of antidiabetic drug metformin against apoptotic cell death in primary cortical neurons. J Mol Neurosci 2008, 34:77-87.

29. Morales Al, Detaille $D$, Prieto $M$, Puente A, Briones E, Arévalo $M$, Leverve $X$ López-Novoa JM, El-Mir MY: Metformin prevents experimental gentamicin-induced nephropathy by a mitochondria-dependent pathway. Kidney Int 2010, 77:861-869.

30. Detaille D, Guigas B, Chauvin C, Batandier C, Fontaine E, Wiernsperger N Leverve $X$ : Metformin prevents high-glucose-induced endothelial cell death through a mitochondrial permeability transition-dependent process. Diabetes 2005, 54:2179-2187.

31. Zmijewski JW, Lorne E, Zhao X, Tsuruta Y, Sha Y, Liu G, Siegal GP, Abraham E: Mitochondrial respiratory complex I regulates neutrophil activation and severity of lung injury. Am J Respir Crit Care Med 2008, 178:168-179.

32. Hinke SA, Martens GA, Cai Y, Finsi J, Heimberg H, Pipeleers D, Van de Casteele M: Methyl succinate antagonises biguanide-induced AMPKactivation and death of pancreatic beta-cells through restoration of mitochondrial electron transfer. Br J Pharmacol 2007, 150:1031-1043.

33. Huckabee WE: Relationships of pyruvate and lactate during anaerobic metabolism. I. Effects of infusion of pyruvate or glucose and of hyperventilation. J Clin Invest 1958, 37:244-254.

34. Suwa M, Egashira T, Nakano $H$, Sasaki H, Kumagai S: Metformin increases the PGC-1alpha protein and oxidative enzyme activities possibly via AMPK phosphorylation in skeletal muscle in vivo. J Appl Physio/ 2006, 101:1685-1692.

35. Nisoli E, Clementi E, Paolucci C, Cozzi V, Tonello C, Sciorati C, Bracale R, Valerio A, Francolini M, Moncada S, Carruba MO: Mitochondrial biogenesis in mammals: the role of endogenous nitric oxide. Science 2003, 299:896-899.

36. Clementi E, Brown GC, Feelisch M, Moncada S: Persistent inhibition of cell respiration by nitric oxide: crucial role of S-nitrosylation of mitochondrial complex I and protective action of glutathione. Proc Natl Acad Sci USA 1998, 95:7631-7636.

37. Zou MH, Kirkpatrick SS, Davis BJ, Nelson JS, Wiles WG IV, Schlattner U, Neumann D, Brownlee M, Freeman MB, Goldman MH: Activation of the AMP-activated protein kinase by the anti-diabetic drug metformin in vivo. Role of mitochondrial reactive nitrogen species. J Biol Chem 2004, 279:43940-51.
38. Castro L, Demicheli V, Tórtora V, Radi R: Mitochondrial protein tyrosine nitration. Free Radic Res 2011, 45:37-52.

39. Ensinger $H$, Weichel $T$, Lindner KH, Grünert $A$, Ahnefeld FW: Effects of norepinephrine, epinephrine, and dopamine infusions on oxygen consumption in volunteers. Crit Care Med 1993, 21:1502-1508.

40. Porta F, Bracht H, Weikert C, Beck M, Takala J, Brandt S, Hiltebrand LB, Jakob SM: Effects of endotoxin and catecholamines on hepatic mitochondrial respiration. Inflammation 2009, 32:315-321.

41. Vuda M, Brander L, Schröeder R, Jakob SM, Takala J, Djafarzadeh S: Effects of catecholamines on hepatic and skeletal muscle mitochondrial respiration after prolonged exposure to faecal peritonitis in pigs. Innate Immun 2012, 18:217-230.

doi:10.1186/cc11332

Cite this article as: Protti et al:: Metformin overdose, but not lactic acidosis per se, inhibits oxygen consumption in pigs. Critical Care 2012 16:R75.

\section{Submit your next manuscript to BioMed Central and take full advantage of:}

- Convenient online submission

- Thorough peer review

- No space constraints or color figure charges

- Immediate publication on acceptance

- Inclusion in PubMed, CAS, Scopus and Google Scholar

- Research which is freely available for redistribution 